\title{
Comparisons of Visual Rust Assessments and DNA Levels of Phakopsora pachyrhizi in Soybean Genotypes Varying in Rust Resistance
}

\author{
C. Paul and C. B. Hill, Department of Crop Sciences, University of Illinois, Urbana 61801; and G. L. Hartman, USDA-ARS and De-
} partment of Crop Sciences, University of Illinois, Urbana 61801

\begin{abstract}
Paul, C., Hill, C. B., and Hartman, G. L. 2011. Comparisons of visual rust assessments and DNA levels of Phakopsora pachyrhizi in soybean genotypes varying in rust resistance. Plant Dis. 95:1007-1012.

Soybean resistance to Phakopsora pachyrhizi, the cause of soybean rust, has been characterized by the following three infection types: (i) immune response (IM; complete resistance) with no visible lesions, (ii) resistant reaction with reddish brown (RB) lesions (incomplete resistance), and (iii) susceptible reaction with tan-colored (TAN) lesions. Based on visual assessments of these phenotypes, single gene resistance in soybean to $P$. pachyrhizi has been documented, but colonization within infected tissues based on fungal DNA (FDNA) levels in different soybean genotypes had not been analyzed. The research used a quantitative polymerase chain reaction (Q-PCR) assay to compare visual disease assessment to FDNA in controlled inoculation experiments using two isolates of $P$. pachyrhizi. The objective of the first experiment was to compare data from digital visual disease assessment to FDNA from Q-PCR assays using digital visual disease assessment using five resistant soybean genotypes (one IM and four RB) and five susceptible genotypes (TAN). The objective of the second experiment was to quantify FDNA using Q-PCR at different time points after inoculation to determine if levels of fungal colonization differed in five

and two TAN). For experiment 1, the numbers of uredinia and uredinia per lesion on four of the five resistant soybean genotypes were lower $(P<0.05)$ than the other six genotypes. Significant differences $(P<$ $0.05)$ in FDNA concentrations were found among soybean genotypes with TAN lesions and among soybean genotypes with RB lesions. Soybean cultivar UG5 (IM phenotype) had significantly less $(P<0.05)$ FDNA than all of the other genotypes. Some genotypes that produced TAN lesions had significantly lower $(P<0.05)$ or non-significantly different FDNA concentrations compared to those genotypes that produced RB lesions. For experiment 2, the regression of FDNA on days after inoculation was significant $(P<0.01)$ with positive slopes for all genotypes except for UG5, in which FDNA declined over time, indicating a reduction of fungal colonization. The results of this QPCR FDNA screening technique demonstrates its use to distinguish different types of resistance, and could be used to facilitate the evaluation of soybean breeding populations, where precise quantification of incomplete and/or partial resistance is needed to identify and map quantitative trait loci.
\end{abstract} soybean genotypes with different levels of resistance (one IM, two RB,
Soybean rust, caused by Phakopsora pachyrhizi H. Sydow \& Sydow, has the potential to cause severe epidemics resulting in significant economic yield losses $(17,28)$. The first report of soybean rust in the continental United States was in 2004 (24). Control measures including fungicide applications and development of cultivars with durable resistance to $P$. pachyrhizi are key components to an integrated rust management program.

Three infection types of $P$. pachyrhizi in soybean were described as (i) immune response (IM; complete resistance) without welldeveloped lesions, (ii) resistant reaction with reddish brown (RB) lesions (incomplete resistance), and (iii) susceptible reaction with tan-colored (TAN) lesions $(3,16)$. These reaction types were used to define dominant, independent, pathotype-specific resistance genes in soybean that control complete or incomplete resistance to $P$. pachyrhizi (8). To date, no pathogen-specific resistance confers resistance to all isolates of $P$. pachyrhizi $(2,21,22)$.

\section{Corresponding author: G. L. Hartman, E-mail: ghartman@illinois.edu}

Trade and manufacturers' names are necessary to report factually on available data; however, the USDA neither guarantees nor warrants the standard of the product, and the use of the name by USDA implies no approval of the product to the exclusion of others that may also be suitable.

* The $e$-Xtra logo stands for "electronic extra" and indicates that two supplementary figures appear in the online edition.

Accepted for publication 31 March 2011.

doi:10.1094/PDIS-10-10-0729

This article is in the public domain and not copyrightable. It may be freely reprinted with customary crediting of the source. The American Phytopathological Society, 2011.
Soybean genotypes with quantitative or partial resistance to $P$. pachyrhizi may have more durable resistance than genotypes with complete or incomplete resistance, as has been shown in other host-pathogen interactions $(15,20)$. To identify plants with partial resistance, quantitative assessments of plant symptoms and pathogen signs are measured. To aid in visual quantitative disease assessments, digital image analysis has successfully been used to measure resistance to oat crown rust (5). Along with visual and digital ratings, direct measurement of pathogen colonization has been accomplished with quantitative polymerase chain reaction (QPCR) technology in other host-pathogen systems $(11,19)$.

Plants with incomplete resistance to pathogens allow some growth or reproduction of the pathogen $(20,23)$. Partial resistance has been defined as reduced fungal colonization or sporulation compared to full susceptibility (20). Incomplete resistance to $P$. pachyrhizi has been defined as an $\mathrm{RB}$ response, while partial resistance is a TAN response with reduced fungal colonization and limited sporulation (16). Expression of both responses may include reduced pustule number, increased length of the latent period, and slower or delayed sporulation throughout the disease cycle $(9,16,27)$. Quantitative assessments of soybean rust resistance have not been widely used because of the time-consuming nature of assessing quantitative traits to select the most resistant plants in large, segregating breeding populations (8). Direct assessment of fungal growth with Q-PCR assays may improve the efficiency and accuracy of assessments of incomplete and partial resistance. The main goal of this research was to use Q-PCR to measure the levels of $P$. pachyrhizi colonization in inoculated leaves of soybean genotypes that phenotypically produce a resistant (complete, incomplete, and partial) or a susceptible reaction. The objectives were to compare the quantity of $P$. pachyrhizi DNA from Q-PCR assays with digital visual disease assessment results, and to quantify fungal DNA (FDNA) using Q-PCR at different time 
points after inoculation to determine if levels of fungal colonization differed in susceptible and resistant soybean genotypes.

\section{Materials and Methods}

Plant and fungal material. For experiment 1,10 soybean genotypes representing different levels of resistance to soybean rust based on previous studies $(4,10,18,21)$, and two isolates of $P$. pachyrhizi (FL07-1 = collected in Florida in 2007 and IL06-1 = collected in Illinois in 2006) with identical virulence (21) were used to compare P. pachyrhizi DNA from Q-PCR assays with digital visual disease assessment (Table 1). Cultivar UG5 seeds were obtained from IITA (International Institute of Tropical Agriculture, Ibadan, Nigeria), while other plant introductions (PI) were obtained from the USDA Soybean Germplasm Collection at Urbana, IL. The two $P$. pachyrhizi isolates chosen produced similar phenotypic reactions on 30 soybean genotypes (21). For experiment 2, five soybean genotypes, UG5, PI 084674, PI 462312, PI 506764, and the susceptible cv. Williams 82 (Table 1), were inoculated separately as previously described with the same two $P$. pachyrhizi isolates to study the progress of colonization by quantifying FDNA at different time points during the infection process.

For both experiments, soybean plants were grown in trays placed in growth chambers (Percival Scientific Inc.), maintained at 20 to $24^{\circ} \mathrm{C}$ at 60 to $70 \%$ relative humidity with $12 \mathrm{~h}$ of $500 \mu \mathrm{mol} \mathrm{m} \mathrm{m}^{-2} \mathrm{~s}^{-1}$ photosynthetically active radiation (PAR) per day. Trays $(52 \times 26$ $\mathrm{cm})$ consisted of 18 cells $(8 \times 8 \mathrm{~cm})$, referred to as pots, filled with soilless mix (LC1) and fertilized with $5 \mathrm{~cm}^{2}$ of 14-14-14 Osmocote (Scotts Miracle-Gro Co.) slow-release fertilizer pellets applied to the surface of each pot. Each pot was over-seeded with three seeds of a single genotype. Three pots of each genotype were planted and watered daily as needed. Leaflets were removed from the third node of 2- to 3-week-old plants, rinsed twice in sterile-distilled water, air-dried in a biological safety cabinet, and transferred to water agar (WA; $15 \mathrm{~g}$ Bacto agar per liter) medium amended with 6-benzylaminopurine (BAP; $1.5 \% \mathrm{vol} / \mathrm{wt}$ ) in $100 \times 15 \mathrm{~mm}$ plates. A single leaflet from each trifoliolate was placed in the WA plates with the abaxial side up ready for inoculation.

Urediniospore inoculum derived from monosporic isolates from Florida and Illinois was increased ex planta through multiple cycles on detached leaflets of Williams 82 (21). Urediniospores were collected with a vacuum-type cyclone spore collector (Barnant Co.).

Inoculation and incubation. In each experiment, urediniospores were suspended in sterile distilled water containing Tween $20(0.01 \%)$ in $15-\mathrm{ml}$ tubes, counted using a hemacytometer, and adjusted as needed to a final suspension of 25 and 50 urediniospores per microliter for experiments 1 and 2, respectively. Experimental units were one leaflet per $100 \times 15 \mathrm{~mm}$ plate. Each leaflet was inoculated with one of the two isolates by placing three $20-\mu \mathrm{l}$ drops of urediniospore suspension separately on each side of the leaflet midrib, spaced equidistantly from each other, for a total of six droplets or inoculation points per leaflet.

Petri dishes containing the inoculated leaflets were sealed in plastic bags (Zipper, Webster Industries) (four dishes per bag) and placed inside an incubator (Percival Scientific) set at 20 to $22^{\circ} \mathrm{C}$ and a 12-h dark-light cycle. Illumination of the leaflets was provided by cool-white fluorescent tubes at $380 \mu \mathrm{mol} \mathrm{m}^{-2} \mathrm{~s}^{-1}$ PAR.

Experimental design. The treatment factors, isolates and genotypes, were arranged in a completely randomized factorial design in both experiments. The experimental unit was one leaflet of a single soybean genotype inoculated with a single rust isolate. Both experiments had three replications of each treatment combination, and each experiment was repeated with a different randomization of experimental units.

Visual disease assessment. For experiment 1, disease development at each of the six inoculation points was visually assessed with a stereoscope (Olympus Corp., Tokyo, Japan)16 days after inoculation. The number of lesions and sporulating uredinia within a 1.7-cm-diameter circle centered at each inoculation point were counted at $\times 100$ magnification. In addition, images at each inoculation point were recorded with a digital camera (QImaging) mounted on the stereoscope, and lesion area within the $1.7-\mathrm{cm}-$ diameter circle containing sporulating uredinia was estimated using MicroSuite Five (Olympus Corp., Lakewood, CO). The mean value of the six inoculation points for each trait (number of lesions, lesion area, and number of sporulating uredinia) was recorded as the value for each experimental unit (single leaflet inoculated with one of the isolates).

Q-PCR measurement of $\boldsymbol{P}$. pachyrhizi colonization. After imaging, a 1.7-cm-diameter cork borer was used to excise leaf tissue including and surrounding each of the six inoculation points within each experimental unit. The six excised leaf disks in an experimental unit in experiment 1 were bulked and placed into 2-ml DNA extraction tubes (Fast DNA Spin Kit-Cat\# 6910-MP Biomedicals) containing Lysing Matrix A, irregular-shaped garnet particles and a single ceramic bead. In experiment 2 , each of the six leaf disks within an experimental unit was collected at different time points $(0,2,4,8,12$, and 16 days) after inoculation and processed separately along with a noninoculated control.

Total DNA (host and pathogen) was extracted from each leaf disk sample following the manufacturer's instructions. In addition, $1 \mu \mathrm{g}$ of carrier salmon sperm DNA and $3 \mu \mathrm{l}$ of $0.05 \%$ Tween 20 solution with CLS-P reagent were added to each sample prior to extraction as recommended by the manufacturer (MP Biomedicals). Samples were homogenized twice in a mechanical bead grinder-FastPrep FP120A instrument (MP Biomedicals) for $40 \mathrm{~s}$ at

Table 1. Name, geographic origin, source of seed, and description of soybean genotypes, with interaction phenotypes produced in response to Phakopsora pachyrhizi isolates FL07-1 and IL06-1

\begin{tabular}{lllll}
\hline Genotype & Geographic origin & Seed source $^{\mathbf{u}}$ & Description & Reaction type $^{\mathbf{v}}$ \\
\hline Williams 82 & Illinois, USA & USDA-ARS & Susceptible check & TAN \\
TGx1835-10E & IITA, Nigeria & IITA & Susceptible & TAN \\
PI 084674 & South Korea & USDA-ARS & Partial resistance & TAN \\
PI 437241 & Moldova & USDA-ARS & Partial resistance & TAN \\
PI 567041A & Indonesia & USDA-ARS & Partial resistance & TAN \\
PI 561377 & Japan & USDA-ARS & Resistant line $^{\mathrm{x}}$ & RB \\
PI 506764 & Japan & USDA-ARS & Source of Rpp3 $_{\text {(Hyuga) }}^{\mathrm{y}}$ & RB \\
PI 462312 & India & USDA-ARS & Source of Rpp 3 gene $^{\mathrm{z}}$ & RB \\
PI 224268 & Australia & USDA-ARS & Resistant line $^{\mathrm{x}}$ & RB \\
UG5 & Uganda & IITA & Resistant line $^{\mathrm{x}}$ & IM \\
\hline
\end{tabular}

" USDA-ARS = United States Department of Agriculture-Agricultural Research Service, Soybean Germplasm Collection, Urbana, IL; and IITA = International Institute of Tropical Agriculture, Ibadan, Nigeria.

${ }^{\vee}$ TAN $=\tan$ lesions (susceptible); RB = red-brown lesions (incomplete resistance); and IM = immune. Both isolates of $P$. pachyrhizi produced identical reaction types on each of the soybean genotypes listed.

${ }^{\text {w } B a s e d ~ o n ~ C h a k r a b o r t y ~ e t ~ a l . ~(4) . ~}$

${ }^{x}$ Based on Paul and Hartman (21).

${ }^{\mathrm{y}}$ Based on Monteros et al. (18).

${ }^{\mathrm{z}}$ Based on Hyten et al. (10). 
a speed setting of $6.0 \mathrm{~m} / \mathrm{s}$ followed by $1 \mathrm{~h}$ incubation at $4^{\circ} \mathrm{C}$. Fifty microliters of $5 \mathrm{mM}$ Tris buffer $(\mathrm{pH}=8.0)$ was added to each homogenate to elute DNA, and the DNA extracts were centrifuged at $13,400 \times g$ for $30 \mathrm{~min}$. From the upper supernatant, $45 \mu \mathrm{l}$ was pipetted into new $1.5-\mathrm{ml}$ tubes, and the DNA was diluted with 1 $\mu \mathrm{g} / \mathrm{ml}$ salmon sperm DNA in $5 \mathrm{mM}$ Tris buffer $(1: 10)$ prior to PCR amplification, in order to minimize the effect of possible PCRinhibitors present in the DNA extraction. Each PCR reaction mixture had $2.5 \mu \mathrm{l}$ sample DNA combined with a $10-\mu \mathrm{lmix}$ that included Platinum QPCR SuperMix-UDG (2x) (Invitrogen), $50 \mathrm{mM}$ $\mathrm{MgCl}_{2}, 10 \mu \mathrm{M}$ P. pachyrhizi primer pair (7), and $0.1 \mu \mathrm{M}$ specific $P$. pachyrhizi DNA probe (7) to make a total of $12 \mu \mathrm{l}$ of reaction mixture. Each sample plus PCR reaction mixture was placed in a separate well in 96-well microtiter plates (Agilent Technologies). A non-DNA template control consisting of sterile water, soybean genomic DNA, and corn rust (Puccinia sorghi) DNA (diluted 1/10) also was included in each plate as an external control. The $P$. pachyrhizi primers and probe were labeled with the 6-carboxyfluorescein (6-FAM) fluorescent reporter dye at the $5^{\prime}$ end and at the $3^{\prime}$ end with the 6-carboxyl-tetramethylrhodamine (TAMRA) dye as a fluorescence quencher (7), and synthesized (Integrated DNA Technologies, Inc.).

FDNA was quantified using the Stratagene (MX3005P) thermal cycler with ROX reference dye. Reaction conditions were initial incubation for $2 \mathrm{~min}$ at $60^{\circ} \mathrm{C}$, denaturing at $95^{\circ} \mathrm{C}$ for $2 \mathrm{~min}$, followed by 40 cycles at $95^{\circ} \mathrm{C}$ for $15 \mathrm{~s}$, and the final step of $30 \mathrm{~s}$ at $60^{\circ} \mathrm{C}$. Threshold cycle $(\mathrm{Ct})$ values were determined for the samples based on cycle threshold. Quantity of $P$. pachyrhizi DNA was estimated from reference dilutions of the DNA standard curve.

The DNA standard curve was constructed from DNA extracted from $0.1 \mathrm{mg}$ of FL07-1 urediniospores, which was quantified $(\mathrm{ng} / \mu \mathrm{l})$ using a Nanodrop ND-1000 spectrophotometer (Thermo Scientific) at $260 \mathrm{~nm}$, and gel electrophoresis was used to determine the integrity of the DNA. FDNA was diluted $1 / 10,1 / 10^{2}$, $1 / 10^{3}$, and $1 / 10^{4}$ to make standard DNA reference stocks. Aliquots of $50 \mu \mathrm{l}$ of DNA reference stocks were stored at $-80^{\circ} \mathrm{C}$. Prior to PCR amplification, $10 \mathrm{ng} / \mu \mathrm{l}$ of soybean leaf genomic DNA was added to each standard DNA reference stock to simulate extraction from rust-infected leaf tissues and to determine possible interference from soybean DNA during PCR amplification. Two replicates of the DNA reference stocks were included in the same PCR plate with a 1/10 dilution of noninfected soybean leaf genomic DNA as a negative control, and PCR amplification was performed as described above. Regression curves of FDNA on $\mathrm{Ct}$ values, as determined by the Stratagene thermocycler software, were plotted for each of the two replications and used to estimate FDNA in each sample.

Statistical analyses. Visual disease assessments and FDNA (pg) values in experiment 1 were transformed using $\log _{10}+1$ prior to analysis to correct for non-homogeneity of variance and non-additivity among the samples (14). Analysis of variance (ANOVA) was performed with the aid of JMP 8 (SAS Institute). Homogeneity of variance among experimental samples was tested using Bartlett's test, and data from different trials within an experiment were pooled for combined analysis if the null hypothesis of equal vari- ance among the trials was not rejected $(P>0.05)$. Simple linear correlations $(r)$ among visual disease traits and FDNA were computed. Least square means for genotypes and isolates or their interaction, when significant, were separated with the Fisher's protected least significant differences (LSD) test at $P<0.05$.

For experiment 2, variation between the main effects, soybean genotypes and $P$. pachyrhizi isolates, their interaction, and sample days after inoculation within main effects was analyzed using JMP MANOVA repeated measures procedure. Linear regression of FDNA on days after inoculation was performed to determine if the relationship between FDNA concentrations and days after inoculation was linear and to compare the relationships between different types of resistance represented in the experiment. The five regression lines were tested for parallelism by using a $t$ test to determine the significance of differences in slopes between any two lines. Lines that did not have significantly different slopes were then tested for differences in intercepts using a $t$ test.

\section{Results}

Interaction phenotypes between 10 soybean genotypes and two isolates of $\boldsymbol{P}$. pachyrhizi. The specific reaction types produced by each of the genotypes when inoculated with each of the two $P$. pachyrhizi isolates were consistent in both experiments (Table 1).

Q-PCR measurement of $P$. pachyrhizi colonization. A standard curve was constructed to normalize amounts of FDNA in pg measured in a dilution series of urediniospore DNA with Q-PCR. The strength of the recorded fluorescence signal incorporated into the PCR amplification product with the amount of FDNA measured was highly correlated $(r=0.99)$. The PCR efficiency as calculated from the reference curve was $101.5 \%$. No P. pachyrhizispecific amplification products were obtained, and no $\mathrm{Ct}$ values were recorded during PCR amplification of the external controls of soybean genomic DNA and the blank of template samples after 40 cycles of amplification. Addition of DNA from noninoculated soybean plants to the standard reference stock DNA did not appear to interfere with the FDNA measurements.

Amplification profiles from replicated samples indicated that reference DNA ranged from $1.1 \mathrm{pg}$ to $1.2 \times 10^{3} \mathrm{pg}$, and $\mathrm{Ct}$ values ranged from 19 to 30 cycles at a delta $\mathrm{Rn}$ (normalized fluorescence) of 0.2. These results validated that PCR amplification and FDNA quantification were reliable over a wide range of DNA levels. Because the regression equations for each replicate were nearly identical, the data were averaged to produce a single reference curve, which was then used to estimate FDNA (pg) in each experimental unit or sample. The $\mathrm{Ct}$ value of the reference standard curve was used to convert $\mathrm{Ct}$ values of the test samples to pg of FDNA.

Assessment of disease resistance traits among soybean genotypes in response to inoculation. The variance between the two trials in experiment 1 was nonsignificant $(P<0.05)$ based on Bartlett's test of the homogeneity for all the traits measured. Therefore, the data were pooled for combined statistical analysis.

There was a significant genotype $\times$ isolate interaction for the number of lesions $(P<0.01)$ and for lesion area $(P<0.05)$, but not for number of uredinia or FDNA (Table 2). However, there were significant $(P<0.01)$ differences among genotypes and isolates for

Table 2. Analyses of variance for number of lesions, number of uredinia, uredinia per lesion, total lesion area, and fungal DNA (pg) produced by two Phakopsora pachyrhizi isolates inoculated on 10 soybean genotypes

\begin{tabular}{lcccccc}
\hline & & \multicolumn{4}{c}{ Mean square } \\
\cline { 3 - 7 } Source of variation & df & Number of lesions $^{\mathbf{w}}$ & Number of uredinia $^{\mathbf{w}}$ & Uredinia per lesion & Lesion area $^{\mathbf{x}}$ & Fungal DNA (pg) $^{\mathbf{y}}$ \\
\hline Isolate & 1 & $0.72^{* * * z}$ & $1.5^{* * *}$ & $0.09^{*}$ & $6.2^{* * *}$ & $24.6^{* * *}$ \\
Genotype & 9 & $0.1^{* *}$ & $16.4^{* * *}$ & $4.1^{* * *}$ & $5.5^{* * *}$ & $118.3^{* * *}$ \\
Genotype $\times$ Isolate & 9 & $0.8^{* *}$ & 0.9 & 0.25 & $1.2^{*}$ & 4.47 \\
Error & 40 & 0.04 & 0.06 & 0.02 & 0.06 & 0.52 \\
\hline
\end{tabular}

${ }^{\mathrm{w}}$ Quantified from circular $1.7-\mathrm{cm}$-diameter digital image of the area surrounding the inoculation point.

${ }^{x}$ Lesion area within the $1.7-\mathrm{cm}$-diameter circle containing sporulating uredinia.

${ }^{y}$ Quantified using quantitative real-time PCR normalized with a standard curve produced from the measurements of six 1.7-cm-diameter leaf disks per replication.

${ }^{\mathrm{z}}$ Significance levels: *, $P<0.05 ; * *, P<0.01 ; * * *, P<0.001$. 
number of uredinia and for FDNA. Significant correlations were found between FDNA (pg) and number of lesions $(r=0.65, P<$ $0.001)$, lesion area $(r=0.69, P<0.001)$, number of uredinia $(r=$ $0.80, P<0.001)$, and uredinia per lesion $(r=0.77, P<0.001)$. Number of lesions was significantly correlated with lesion area $(r$ $=0.5, P=0.01)$, number of uredinia $(r=0.67, P<0.001)$, and uredinia per lesion $(r=0.45, P=0.04)$. In contrast, lesion area was not significantly $(P=0.04)$ correlated with number of uredinia $(r=$ $0.2)$ or uredinia per lesion $(r=0.19)$.

Soybean genotype UG5 had an immune response (complete resistance) to inoculation with both isolates (Table 1). Genotypes that had an $\mathrm{RB}$ reaction to both isolates (Table 1) produced fewer $(P<0.05)$ uredinia and uredinia per lesion, and had less FDNA than genotypes with a TAN reaction, with the exception of PI 437241, which had FDNA quantities not significantly $(P>0.05)$ different from PI 462312 (Rpp3) expressing an RB reaction (Table

Table 3. Mean number of uredinia, uredinia per lesion, and fungal DNA on detached leaflets of 10 soybean genotypes after inoculation with two Phakopsora pachyrhizi isolates based on two trials

\begin{tabular}{lcccc}
\hline $\begin{array}{l}\text { Soybean } \\
\text { genotype }\end{array}$ & $\begin{array}{c}\text { Reaction } \\
\text { type }^{\mathbf{w}}\end{array}$ & $\begin{array}{c}\text { Number of }_{\text {uredinia }^{\mathbf{x}}} \\
\text { Williams 82 }\end{array}$ TAN & $\begin{array}{c}\text { Uredinia } \\
\text { per lesion }^{\mathbf{x}}\end{array}$ & $\begin{array}{c}\text { Fungal } \\
\text { DNA (pg) }\end{array}$ \\
TGx1835-10E & TAN & $6.5 \mathrm{a}$ & $1.9 \mathrm{a}$ & $581 \mathrm{a}$ \\
PI 084674 & TAN & $6.6 \mathrm{a}$ & $1.8 \mathrm{a}$ & $624 \mathrm{a}$ \\
PI 567041A & TAN & $4.1 \mathrm{~b}$ & $1.3 \mathrm{~b}$ & $219 \mathrm{~b}$ \\
PI 561377 & RB & $3.2 \mathrm{~b}$ & $1.1 \mathrm{~b}$ & $324 \mathrm{ab}$ \\
PI 437241 & TAN & $1.9 \mathrm{c}$ & $0.5 \mathrm{c}$ & $72 \mathrm{c}$ \\
PI 462312 & RB & $0.5 \mathrm{~d}$ & $0.1 \mathrm{~d}$ & $43 \mathrm{~cd}$ \\
$\quad$ Rpp3) & & & & \\
PI 506764 & RB & $0.1 \mathrm{de}$ & $0.0 \mathrm{~d}$ & $23 \mathrm{~d}$ \\
(Rpp3 Hyuuga) & & & & \\
PI 224268 & RB & $0.1 \mathrm{de}$ & $0.0 \mathrm{~d}$ & $8 \mathrm{e}$ \\
UG5 & IM & $0.0 \mathrm{e}$ & $0.0 \mathrm{~d}$ & $0 \mathrm{f}$ \\
\hline
\end{tabular}

${ }^{\mathrm{w}} \mathrm{TAN}=\tan$ lesions (susceptible); RB = red-brown lesions (incomplete resistance); and $\mathrm{IM}=$ immune.

${ }^{x}$ Quantified from a digital image of the circular 1.7-cm-diameter area surrounding the inoculation point.

${ }^{y}$ Quantified using quantitative real-time PCR normalized with a standard curve produced from the measurements of six $1.7-\mathrm{cm}$-diameter leaf disks per replication.

${ }^{\mathrm{z}}$ Means within each column followed by the same letter are not significantly different at $P<0.05$.
3). The number of uredinia for UG5 did not differ from PI 224268 or PI 506764. The number of uredinia per lesion for UG5 did not differ from PI 224268, PI 462312 (Rpp3), or PI 506764, whereas FDNA was less $(P<0.05)$ for UG5 than those three genotypes. PI 437241 , with a TAN reaction to both isolates, had fewer $(P<0.05)$ uredinia per lesion and less FDNA than PI 561377, expressing an $\mathrm{RB}$ reaction to either isolate, and PI 084674, PI 567041A, TGx 1835-10E, and Williams 82, which produced TAN reactions. While PI 437241 had a greater $(P<0.05)$ number of uredinia and uredinia per lesion than PI 462312 and PI 506764, both produced an RB reaction; PI 437241 FDNA was not different $(P>0.05)$ from PI 462312.

The significant interaction between soybean genotypes and $P$. pachyrhizi isolates was primarily attributed to the lack of difference in lesion area they produced on PI 084674, whereas lesion area produced by isolate FL07-1 on each of the soybean genotypes was greater $(P<0.05)$ than that produced by IL06-1 overall (Table 2, Fig. 1). The lesion area produced by FL07-1 on PI 084674 also was significantly less $(P<0.05)$ than that produced on PI 462312 and PI 224268, which had RB reaction to both isolates. The lesion area produced by isolate IL06-1 was greater $(P<0.05)$ on Williams 82 and PI 084674 than on the other soybean genotypes that had similarly sized lesion areas. Lesion area produced by FL07-1 on all genotypes with an RB reaction was not different $(P>0.05)$ from Williams 82, TGx1835-10E, or PI 567041A, which produced TAN lesions. Results for the number of lesions were not presented because the data were correlated $(r=0.49, P=0.002)$ to the lesion area.

Assessment of $P$. pachyrhizi FDNA over time using Q-PCR. Bartlett's test of homogeneity of variance was not significant $(P>$ 0.05 ) for the Q-PCR measurements of FDNA at six sampling times on the five soybean genotypes inoculated with two isolates in the two trials. Therefore, the data from both trials were pooled for repeated measures analysis. There was no interaction between the main effects, isolates and genotypes, for FDNA quantity $(P>0.05)$ (Table 4). There were differences among the isolates $(P<0.05)$ and among the genotypes $(P<0.001)$. There was a significant $(P<$ 0.05 ) effect for sample days within isolates and genotypes, and a significant $(P<0.001)$ effect for sample days within genotypes for FDNA.

Quantity of FDNA (pg) in Williams 82 was greater $(P<0.05)$ than in PI 5067644 days after inoculation, while the quantity of

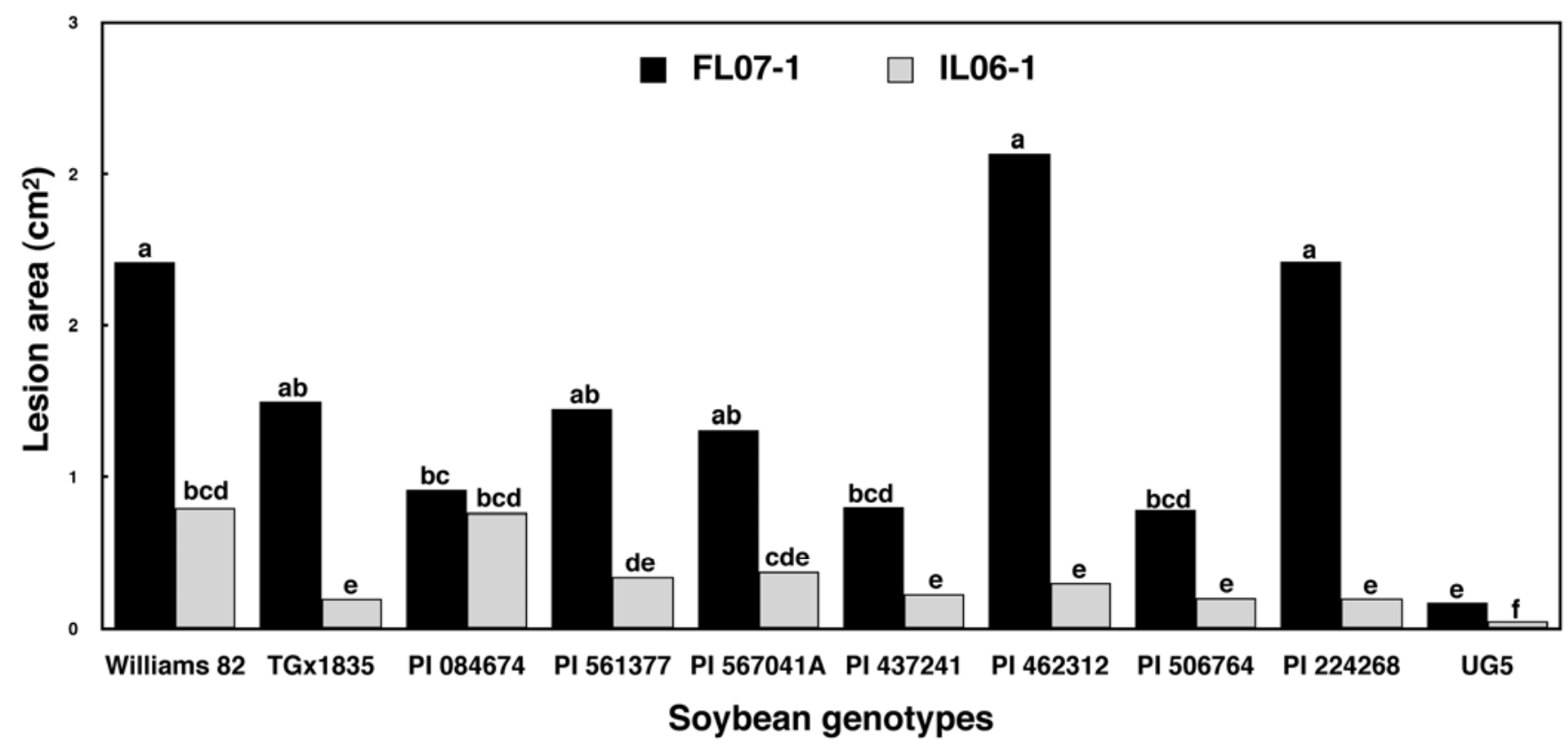

Fig. 1. Lesion area on 10 soybean genotypes inoculated with two Phakopsora pachyrhizi isolates. Bars labeled with the same letter are not significantly different at $P<0.05$. Data from two experiments were pooled for analysis. 
FDNA in UG5 declined steadily 8 days after inoculation (Fig. 2A). The regression of FDNA on days after inoculation was significant $(P<0.01)$ for all genotypes except for UG5 (Fig. 2B). The regression lines appeared to follow the same trends as the plots of FDNA versus days after inoculation (Fig. 2A) for each soybean genotype, with the regression line for UG5 having a negative slope $(b=-0.02$ \pm 0.02 ), indicating an overall decline in FDNA. The regression lines for Williams $82(b=0.16 \pm 0.02)$, PI $084674(b=0.15 \pm$ $0.01)$, PI $462312(b=0.12 \pm 0.02)$, and PI $506764(b=0.11 \pm$ 0.02 ) had positive slopes. The $t$ tests to compare slopes indicated that the slope for UG5 differed $(P<0.001)$ from all the other genotypes, while slopes for PI 462312 and PI 506764 regression lines differed $(P<0.02$ and $P<0.01$, respectively) from the slope of the regression line for Williams 82 . None of the intercepts of parallel regression lines were significantly $(P>0.05)$ different, indicating similarity in initial inoculum dose.

\section{Discussion}

The main objective of this study was to determine if soybean genotypes with incomplete or partial resistance to $P$. pachyrhizi could be distinguished by Q-PCR technology. Based on our findings, we conclude that this technique can help distinguish different kinds of resistance, such as complete (immunity), incomplete (RB), and partial resistance from each other and from susceptibility. This ability will facilitate the development of soybean rust resistant cultivars by increasing precision in selection of resistant plants in segregating populations derived from crosses between parents with different levels of incomplete or partial resistance and when accurate evaluation of resistance phenotypes is required to identify and map quantitative trait loci.

Q-PCR evaluation of soybean rust resistance based on FDNA concentrations was positively correlated with visual assessment of the number of uredinia in our study. A similar positive and significant correlation was reported for FDNA concentrations detected in plant tissue to visual disease ratings for Verticillium wilt in alfalfa (13), Phytophthora root rot in pepper (25), Fusarium ear blight of wheat (6), and Alternaria leaf blight of carrot (1). Recently, Q-PCR was used to determine the extent of $P$. pachyrhizi colonization in kudzu, reporting a 10-fold increase in FDNA concentration in the susceptible kudzu compared to the resistant kudzu, which was similar to our results (12).

Comparison of FDNA in soybean genotypes with different types of resistance revealed differences not evident when signs and symptoms were evaluated visually. As expected from the visual assessments, most soybean genotypes with an RB reaction type had fewer uredinia and uredinia per lesion and had less FDNA than genotypes with a TAN reaction type; however, Q-PCR revealed an exception in the case of PI 561377, which expressed an RB phenotype but had a similar level of rust colonization to the TAN genotypes. Q-PCR measurements of FDNA present in tissues inoculated with $P$. pachyrhizi resolved the extent of colonization more pre-

Table 4. Multivariate analysis of variance for fungal DNA quantitative polymerase chain reaction (Q-PCR) measurements at $0,2,4,8,12$, and 16 days postinoculation in five soybean genotypes inoculated with two isolates of Phakopsora pachyrhizi

\begin{tabular}{lcc}
\hline Source of variation & df & $\boldsymbol{F}$ test value \\
\hline Between main effects & & \\
$\quad$ Isolate & 1 & $4.4^{*}$ \\
Genotype & 4 & $14.2^{* * *}$ \\
Isolate $\times$ Genotype & 4 & 0.2 \\
Sample days within main effects & & \\
Sample day & 5 & $130.5^{* * *}$ \\
Isolate $\times$ Day & 5 & 0.7 \\
Genotype $\times$ Day & 20 & $5.6^{* * *}$ \\
Isolate $\times$ Genotype $\times$ Day & 20 & $2.0^{*}$ \\
\hline
\end{tabular}

y Significance levels: $*, P<0.05 ; * * *, P<0.001$.

${ }^{\mathrm{z}}$ The multivariate $F$ test was used to determine significance, because the Pillai's trace test indicated that use of a univariate $F$ test was inappropriate. Sphericity test with Mauchley criterion was highly significant. cisely than visual digital assessment. For instance, FDNA but not the numbers of uredinia or uredinia per lesion differentiated the three soybean genotypes expressing complete (immune, UG5) or incomplete (RB reaction; PI 506764 and PI 224268) resistance.

In our study, PI 437241 had significantly lower numbers of uredinia, uredinia per lesion, and FDNA than the other soybean genotypes with TAN reactions. The use of QPCR to measure fungal colonization has been successfully used to differentiate susceptible genotypes from partially resistant genotypes in other host-pathogen systems $(1,11)$. Partial resistance, as expressed in our study, appeared to limit the extent of colonization and subsequent sporulation, based respectively on FDNA measurements and observations of fewer sporulating uredinia associated with the resistance. This resistance may be more durable than immunity (complete resistance) because it potentially reduces the selection for increased virulence put on the pathogen population as reproduction still occurs on host plants, although at a lower level than on fully susceptible genotypes (20).

FDNA and the number of uredinia were not significantly different between PI 462312 (Rpp3) and PI 506764 (Rpp3 Hyuuga) after inoculation with both $P$. pachyrhizi isolates, suggesting that the two genotypes share the same resistance gene at the Rpp3 locus (18). However, the differences in lesion area between these two genotypes suggested that the two resistance genes may be different alleles of the Rpp3 locus expressing different levels of resistance.
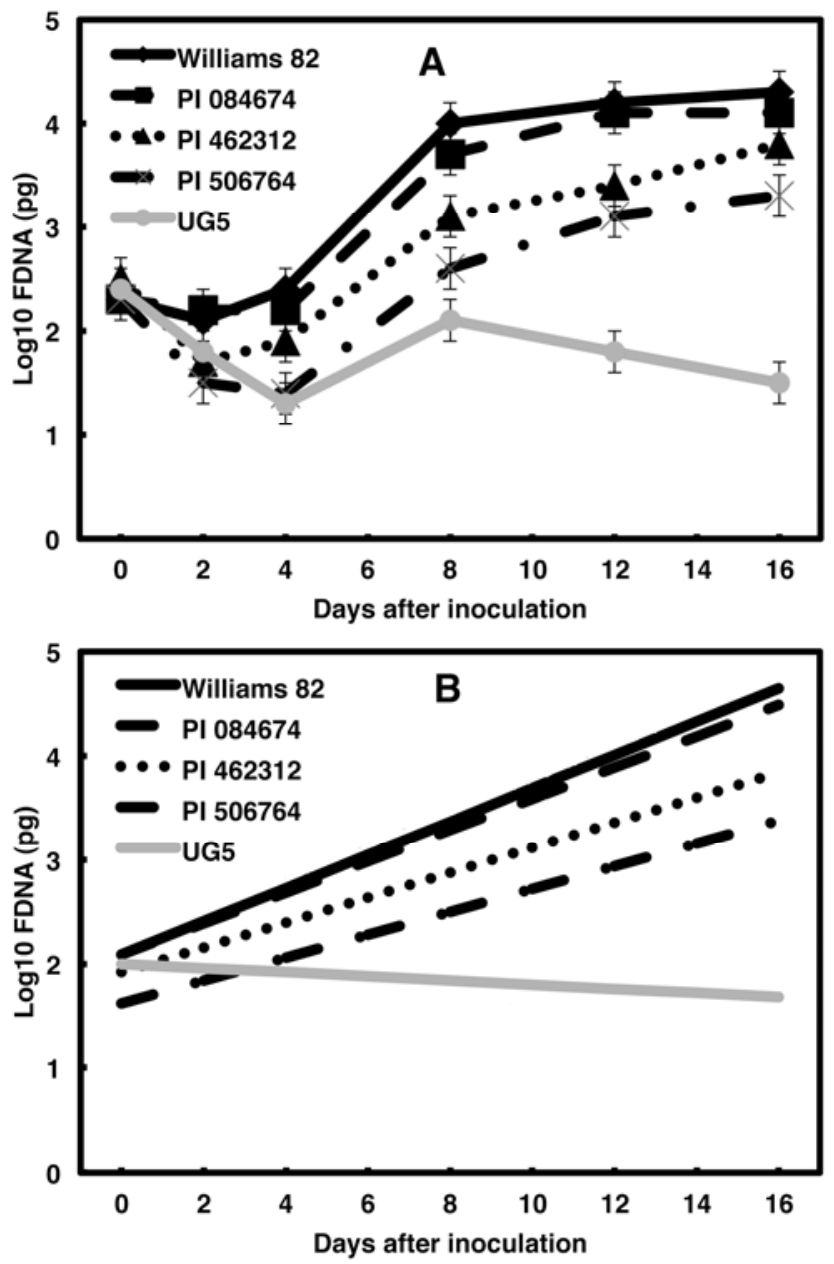

Fig. 2. Quantity of fungal DNA (FDNA) in leaflets of five soybean genotypes inoculated with isolates FL07-1 and IL06-1 of Phakopsora pachyrhizi measured by quantitative polymerase chain reaction. A, FDNA (pg) 0 to 16 days after inoculation. Data from two isolates of $P$. pachyrhizi were pooled. B, Regression of FDNA (pg) against days after inoculation: Williams 82 , FDNA $(p g)=2.09+0.16$ (day), $R^{2}=$ 0.63; PI 084674, FDNA (pg) $=2.09+0.15$ (day), $R^{2}=0.61 ; \mathrm{PI} 462312$ (Rpp3), FDNA (pg) $=1.92+0.12$ (day), $R^{2}=0.43 ;$ PI 506764 (Rpp3-Hyuuga), FDNA (pg) = $1.62+0.11$ (day), $R^{2}=0.38 ;$ UG5, FDNA $(\mathrm{pg})=2.01-0.02$ (day), $R^{2}=0.03$. 
Progression of colonization of $P$. pachyrhizi on susceptible, partially resistant, and incompletely resistant soybean genotypes, as measured by Q-PCR, was similar to the progression found in moderately resistant oats infected with crown rust caused by Puccinia coronata (11). Colonization in UG5 (complete resistance) declined rapidly between 0 and 4 days postinoculation, increased until 8 days after inoculation, and declined through 16 days after inoculation. It was at 4 days after inoculation when differentiation of rust colonization among the soybean genotypes began to appear, similar to the progression of colonization in the oat-crown rust study (11) and for Phytophthora capsici in peppers (25). In an analysis of soybean transcriptome changes in response to soybean rust infection, it was shown that incomplete resistance expressed by the soybean rust resistance gene Rpp 2 occurred prior to 3 days after inoculation; however, the progression of rust colonization was not monitored (26). It is possible that the expression of the complete resistance in UG5 was also initiated 3 days after inoculation or earlier, but FDNA did not begin to decrease until 8 days after inoculation in our study.

Of the signs and symptoms of soybean rust measured in this study, there was a differential interaction between soybean genotypes and the two isolates for lesion area only. In addition, the larger lesion area produced by the $P$. pachyrhizi FL07-1 isolate suggested that this isolate was more aggressive than the IL06-1 isolate. Although it is well known that there are differences in virulence among isolates of $P$. pachyrhizi $(2,21,22)$, our results also indicate a difference in aggressiveness between the two U.S. isolates.

\section{Acknowledgments}

We thank the Soybean Diseases Biotechnology Center at the University of Illinois and the United Soybean Board for partial financial support of this research. We thank Lauren Beck who assisted with digital images. We also thank R. L. Nelson and his staff at the USDA Soybean Germplasm Collection Center, Urbana, IL, for providing soybean seeds used in this study.

\section{Literature Cited}

1. Boedo, C., Berruyer, R., Lecomte, M., Bersihand, S., Briard, M., Le Clerc, V., Simoneau, P., and Poupard, P. 2010. Evaluation of different methods for the characterization of carrot resistance to the alternaria leaf blight pathogen (Alternaria dauci) revealed two qualitatively different resistances. Plant Pathol. 59:368-375.

2. Bonde, M. R., Nester, S. E., Austin, C. N., Stone, C. L., Frederick, R. D., Hartman, G. L., and Miles, M. R. 2006. Evaluation of virulence of Phakopsora pachyrhizi and P. meibomiae isolates. Plant Dis. 90:708716.

3. Bromfield, K. R., and Hartwig, E. E. 1980. Resistance to soybean rust and mode of inheritance. Crop Sci. 20:254-255.

4. Chakraborty, N., Curley, J., Frederick, R. D., Hyten, D. L., Nelson, R. L., Hartman, G. L., and Diers, B. W. 2009. Mapping and confirmation of a new allele at Rppl from soybean PI 594538A conferring RB lesion-type resistance to soybean rust. Crop Sci. 49:783-790.

5. Diaz-Lago, J. E., Stuthman, D. D., and Leonard, K. J. 2003. Evaluation of components of partial resistance to oat crown rust using digital image analysis. Plant Dis. 87:667-674.

6. Doohan, F. M., Parry, D. W., and Nicholson, P. 1999. Fusarium ear blight of wheat: The use of quantitative PCR and visual disease assessment in studies of disease control. Plant Pathol. 48:209-217.

7. Frederick, R. D., Snyder, C. L., Peterson, G. L., and Bonde, M. R. 2002. Polymerase chain reaction assays for the detection and discrimination of the soybean rust pathogens Phakopsora pachyrhizi and $P$. meibomiae. Phytopathology 92:217-227.

8. Hartman, G. L., Miles, M. R., and Frederick, R. D. 2005. Breeding for resistance to soybean rust. Plant Dis. 89:664-666.

9. Hartman, G. L., Wang, T. C., and Tschanz, A. T. 1991. Soybean rust development and the quantitative relationship between rust severity and soybean yield. Plant Dis. 75:596-600.

10. Hyten, D. L., Smith, J., Frederick, R., Tucker, M., Song, Q., and Cregan, P. 2009. Bulked segregant analysis using the GoldenGate Assay to locate the Rpp3 locus that confers resistance to soybean rust in soybean. Crop Sci. 49:265-271.

11. Jackson, E. W., Avant, J. B., Overturf, K. E., and Bonman, J. M. 2006. A quantitative assay of Puccinia coronata f. sp. avenae DNA in Avena sativa. Plant Dis. 90:629-636.

12. Jordon, S. A., Mailhot, D. J., Gevens, A. J., Marios, J. J., Wright, D. L., Harmon, C. L., and Harmon, P. F. 2010. Characterization of kudzu (Pueraria spp.) resistance to Phakopsora pachyrhizi, the causal agent of soybean rust. Phytopathology 100:941-948.

13. Larsen, R. C., Vandemark, G. J., Hughes, T. J., and Grau, C. R. 2006. Development of a real-time polymerase chain reaction assay for quantifying Verticillium albo-atrum DNA in resistant and susceptible alfalfa. Phytopathology 96:1519-1525.

14. Little, T. M., and Hill, F. J. 1978. Agricultural Experimentation. Wiley, New York.

15. McDonald, B. A., and Linde, C. 2002. The population genetics of plant pathogens and breeding strategies for durable resistance. Euphytica 124:163-180.

16. Miles, M. R., Bonde, M. R., Nester, S. E., Berner, D. K., Frederick, R. D., and Hartman, G. L. 2011. Characterizing resistance to Phakopsora pachyrhizi in soybean. Plant Dis. 95:577-581.

17. Miles, M. R., Frederick, R. D., and Hartman, G. L. 2003. Soybean Rust: Is the U.S. soybean crop at risk? In: APSnet Feature APS Net Plant Pathology Online.

18. Monteros, M. J., Ha, B.-K., Phillips, D. V., and Boerma, H. R. 2010. SNP assay to detect the 'Hyuuga' red-brown lesion resistance gene for Asian soybean rust. Theor. Appl. Genet. 121:1023-1032.

19. Oliver, R. P., Rybak, K., Shankar, M., Loughman, R., Harry, N., and Solomon, P. S. 2008. Quantitative disease resistance assessment by realtime PCR using the Stagonospora nodorum-wheat pathosystem as a model. Plant Pathol. 57:527-532.

20. Parlevliet, J. E. 1979. Components of resistance that reduce the rate of epidemic development. Annu. Rev. Phytopathol. 17:203-222.

21. Paul, C., and Hartman, G. L. 2009. Sources of soybean rust resistance challenged with single-spored isolates of Phakopsora pachyrhizi collected from the USA. Crop Sci. 49:1781-1785.

22. Pham, T. A., Miles, M. R., Frederick, R. D., Hill, C. B., and Hartman, G. L. 2009. Differential responses of resistant soybean entries to isolates of Phakopsora pachyrhizi. Plant Dis. 93:224-228.

23. Ribeiro Do Vale, F. X., Parlevliet, J. E., and Zambolim, L. 2001. Concepts in plant disease resistance. Fitopatol. Bras. 26:577-589.

24. Schneider, R. W., Hollier, C. A., Whitam, H. K., Palm, M. E., McKemy, J M., Hernandez, J. R., Levy, L., and DeVries-Paterson, R. 2005. First report of soybean rust caused by Phakopsora pachyrhizi in the continental United States. Plant Dis. 89:774.

25. Silvar, C., Díaz, J., and Merino, F. 2005. Real-time polymerase chain reaction quantification of Phytophthora capsici in different pepper genotypes. Phytopathology 95:1423-1429.

26. Van de Mortel, M., Recknor, J. C., Graham, M. A., Nettleton, D., Dittman, J. D., Nelson, R. T., Godoy, C. V., Abdelnoor, R. V., Almeida, Á. M. R. Baum, T. J., and Whitham, S. A. 2007. Distinct biphasic mRNA changes in response to Asian soybean rust infection. Mol. Plant-Microbe Interact. 20:887-899.

27. Wang, T. C., and Hartman, G. L. 1992. Epidemiology of soybean rust and breeding for host resistance. Plant Prot. Bull. 34:109-124.

28. Yorinori, J. T., Paiva, W. M., Frederick, R. D., Costamilan, L. M. Bertagnolli, P. F., Hartman, G. L., Godoy, C. V., and Nunes, J., Jr. 2005. Epidemics of soybean rust (Phakopsora pachyrhizi) in Brazil and Paraguay from 2001-2003. Plant Dis. 89:675-677. 